\title{
CONTRIBUIÇÕES DA NEUROPSICOLOGIA: ALTAS HABILIDADES/SUPERDOTAÇÃO
}

\section{ARTIGO DE REVISÃO}

GALVÃO, Jéssyca de Alcantara ${ }^{1}$

GALVÃO, Jéssyca de Alcantara. Contribuições da Neuropsicologia: Altas Habilidades/Superdotação. Revista Científica Multidisciplinar Núcleo do Conhecimento. Ano 05, Ed. 03, Vol. 06, pp. 41-70. Março de 2020. ISSN: 2448-0959, Link de acesso: https://www.nucleodoconhecimento.com.br/psicologia/altashabilidades-superdotacao

\section{RESUMO}

A Neuropsicologia é um campo da psicologia e das neurociências que estuda as relações entre o sistema nervoso central, o funcionamento cognitivo e o comportamento. Desde os primórdios, os pesquisadores da área buscam compreensões à respeito da anatomia do cérebro e a sua correlação com as habilidades cognitivas. A neuropsicologia está em constante avanço e transformação, e, dessa forma, os achados dessa ciência oferecem cada vez mais respaldo teórico e metodológico para os profissionais e possibilitam intervenções e tratamentos mais adequados aos pacientes. Apesar dos avanços em pesquisa acerca das habilidades cognitivas, atualmente ainda existem dificuldades quanto ao reconhecimento de indivíduos com Altas Habilidades/Superdotação. Além disso, em muitas das vezes, confunde-se AH/SD com transtornos. Por essa razão, este estudo bibliográfico apresenta as principais contribuições da Neuropsicologia para a identificação e desenvolvimento de pessoas com $\mathrm{AH} / \mathrm{SD}$, denotando os aspectos históricos, os

\footnotetext{
${ }^{1}$ Especialista em Neuropsicologia; Especialista em Avaliação Psicológica Clínica e Institucional; Especialista em Psicologia de Trânsito; Graduação em Pedagogia; Graduação em Psicologia.
} 
principais avanços e o cenário atual. A análise dos dados coletados em artigos, teses, livros, leis e políticas públicas vigentes evidenciou que ainda não existe uma classificação precisa para a compreensão das AH/SD. O que se sabe atualmente é que a inteligência é um dos fatores para a identificação, porém outras aptidões também são consideradas como os aspectos artísticos, motivacionais e a capacidade de liderança. Há, ainda, a associação dos resultados de testes psicológicos com exames de neuroimagem. Em continuidade a investigação, averiguou-se os mecanismos neuropsicológicos de pessoas identificadas com AH/SD. Os resultados das pesquisas examinadas apontam uma relação entre o quociente intelectual e a atividade cerebral bem como indicativos de diferenças no funcionamento e anatomia do cérebro dessas pessoas quando comparadas com sujeitos de quociente intelectual médio. O último tópico aborda a realidade brasileira de crianças e adolescentes com $\mathrm{AH} / \mathrm{SD}$ na perspectiva escolar, as dificuldades quanto ao processo de identificação e o atendimento adequado para esses indivíduos.

Palavras-chave: Neuropsicologia, altas habilidades, superdotação.

\section{INTRODUÇÃO}

As Altas Habilidades/Superdotação (AH/SD) ainda é uma temática pouco explorada, com divergências teóricas, mas em expansão no Brasil. Nesse cenário, as investigações em Neuropsicologia apontam significativas contribuições, sendo essa a ciência que estuda as ligações entre o sistema nervoso central, o funcionamento cognitivo e o comportamento. Observa-se como problemática que, atualmente, as pesquisas em Neuropsicologia possuem grande enfoque nos transtornos globais do desenvolvimento, e, além disso, ainda não existe um consenso entre autores a respeito do processo de Avaliação Neuropsicológica e diagnóstico de AH/SD. Por conseguinte, esse estudo se justifica, pois, no Brasil, existem dificuldades e limitações no diagnóstico precoce de crianças com $\mathrm{AH} / \mathrm{SD}$, fato que gera obstáculos para o atendimento adequado e estímulos fundamentais para o desenvolvimento dos potenciais humanos. 
O tema ainda é visto como fenômeno raro e possui compreensões errôneas. Em razão dessas limitações, atualmente poucas escolas ofertam atendimento especializado aos indivíduos diagnosticados com AH/SD. Nesse cenário, Souza (2013) aponta que muitos alunos com altas habilidades e superdotação podem apresentar rendimento acadêmico inferior ao nível de estudo do qual está inserido, demonstrando desmotivação e dificuldades de socialização. Essa realidade evidência a importância da presente pesquisa. Logo, faz-se necessário observar de que modo a Neuropsicologia pode contribuir no processo de identificação das AH/SD, considerando as funções cognitivas e o comportamento. Objetiva-se com o estudo investigar as contribuições da Neuropsicologia para a identificação e desenvolvimento de pessoas com Altas Habilidades/Superdotação.

À vista disso, pretende-se averiguar de que modo a Neuropsicologia classifica as $\mathrm{AH} / \mathrm{SD}$; abordar os mecanismos neuropsicológicos de pessoas identificadas com $\mathrm{AH} / \mathrm{SD}$ e realizar um levantamento da realidade brasileira de crianças e adolescentes com AH/SD na perspectiva escolar. A proposta metodológica desse estudo é a realização de uma pesquisa bibliográfica cujo intento é o levantamento de informações acerca das contribuições da Neuropsicologia na identificação de sujeitos com AH/SD e os atributos relevantes para o desenvolvimento dos seus potenciais. Conforme Severino (2007), a pesquisa bibliográfica é aquela que se realiza a partir de um registro disponível e é decorrente de pesquisas anteriores. Apoia-se em documentos impressos, livros, artigos e teses acadêmicas. Utiliza-se dos dados teóricos que já foram trabalhados por outros pesquisadores e os registra.

O trabalho, portanto, será realizado de forma analítica e, dessa forma, considerará as contribuições teóricas e metodológicas existentes. Os dados da pesquisa serão analisados sob a perspectiva do método qualitativo. De acordo com Lüdke e André (1986), na abordagem teórico- qualitativa os dados descritivos e os extratos documentais são excelentes para subsidiar uma informação ou esclarecer questionamentos. Por essa razão, serão considerados os dados relevantes ao objetivo proposto. A coleta de informações será feita por meio de pesquisas disponíveis em artigos, teses, livros, leis e políticas públicas vigentes, considerando 
autores cujo enfoque teórico é a Neuropsicologia. Será averiguado, também, por que a $\mathrm{AH} / \mathrm{SD}$ ainda é um tema pouco explorado. Essa pesquisa considera, também, os principais avanços e colaborações de estudos advindos da Neuropsicologia.

\section{HISTÓRICO}

Altas Habilidades/Superdotação (AH/SD) ainda é um tema de pesquisa pouco explorado e que está em expansão no Brasil. Inicialmente, faz-se necessário apresentar quando esse tema começou a ser estudado e os principais avanços gerados e presentes na atualidade. Conforme Merlo (2008), as primeiras abordagens relacionadas à questão das Altas Habilidades/ Superdotação ocorreram no Brasil em 1929, iniciadas pela psicóloga e pedagoga Helena Antipoff, e, posteriormente, houve o desenvolvimento de pesquisas na área. Apesar de não ser um tema novo, ainda é um assunto pouco explorado pelos pesquisadores da atualidade. A primeira manifestação explícita do tema na política de Educação Brasileira aconteceu em 1971, com a Lei $n^{0}$ 5.692, de 11 de agosto de 1971, Art. 9으, que fixou Diretrizes e Bases para o ensino de $1^{\circ}$ e $2^{\circ}$ grau.

Os alunos que apresentarem deficiências físicas ou mentais, os que se encontrarem em atraso considerável quanto à idade regular de matrícula e os superdotados deverão receber tratamento especial, de acordo com as normas fixadas pelos competentes Conselhos de Educação (BRASIL, 1971).

Desde então houve avanços, e, dessa forma, a Lei 13.234, de 29 de dezembro de 2015 dispõe sobre a identificação, o cadastramento e o atendimento na educação básica e na educação superior de alunos com AH/SD.

O poder público deverá instituir cadastro nacional de alunos com altas habilidades ou superdotação matriculados na educação básica e na educação superior, a fim de fomentar a execução de políticas públicas destinadas ao desenvolvimento pleno das potencialidades desse alunado (BRASIL, 2015). 
O objetivo dessa Lei é o desenvolvimento de políticas públicas que contemplem esse público com $\mathrm{AH} / \mathrm{SD}$, de modo a proporcionar o pleno desenvolvimento do potencial. Entretanto, faz-se necessário questionar sobre como será realizada a identificação desses alunos. Atualmente, a dificuldade no reconhecimento desses indivíduos interfere significativamente no processo de aprendizagem, e, em muitas das vezes, confunde-se AH/SD com hiperatividade e falta de interesse, situação que culmina em repetência e evasão escolar. Considerando as dificuldades no reconhecimento dos indivíduos com AH/SD, nota-se a importância das contribuições da Neuropsicologia no processo de identificação.

\subsection{DE QUE MODO A NEUROPSICOLOGIA CLASSIFICA AS ALTAS HABILIDADES/SUPERDOTAÇÃO}

Para compreender de que modo a Neuropsicologia classifica as Altas habilidades/Superdotação faz-se necessário elucidar qual o estudo dessa ciência. Segundo Miotto, Lúcia e Scaff (2018), a Neuropsicologia é a área da psicologia e das neurociências que estuda as relações entre o sistema nervoso central, o funcionamento cognitivo e o comportamento. No âmbito clínico, objetiva-se com a avaliação neuropsicológica: auxiliar no diagnóstico diferencial de quadros neurológicos e neuropsiquiátricos; tratamentos clínicos medicamentosos e cirúrgicos e planejar e monitorar programas de reabilitação voltados para as alterações cognitivas, comportamentais e do cotidiano do paciente. Conforme Miotto, Lúcia e Scaff (2018), é importante ressaltar que a avaliação neuropsicológica não pode ser limitada à aplicação e correção de testes cognitivos. Assim, faz-se necessário rastrear a extensão da alteração cognitiva, verificar as funções comprometidas e as preservadas, observar se existe a presença de alterações de humor e os impactos ocasionados no contexto pessoal, social e ocupacional do indivíduo.

De acordo com Merlin (2012 apud SILVA; ROLIM; MAZOLI, 2016), a Neuropsicologia surgiu da observação clínica de pacientes que haviam sofrido lesões cerebrais. Inicialmente, visava-se estudar a localização das diferentes funções cognitivas cerebrais, mas com os avanços da tecnologia surgiram técnicas de neuroimagem 
estrutural e funcional, o que possibilitou fidedignidade na localização de comportamentos e de habilidades cerebrais. Esse avanço possibilitou maior compreensão dos casos clínicos, propostas de tratamento mais adequadas, elucidações de prognósticos e avanços em pesquisas. Observa-se por meio das pesquisas apresentadas que desde os primórdios a Neuropsicologia busca estudar as habilidades cognitivas; fundamentando-se nas dificuldades e facilidades apresentadas pelo indivíduo em seu cotidiano. Essa ciência está em constante avanço e transformação, propiciando cada vez mais respaldo para os profissionais da área e beneficiários desse sistema: os pacientes.

\subsection{AVALIAÇÃO DA INTELIGÊNCIA DE PESSOAS COM ALTAS HABILIDADES/SUPERDOTAÇÃO}

Nesse cenário de avanços, é importante destacar como surgiu a Avaliação da inteligência de pessoas com Altas Habilidades/Superdotação. Sendo assim, Silva, Rolim e Mazoli (2016) apontam a Psicometria como a área responsável pela elaboração de instrumentos de mensuração de inteligência. Sousa (2009 apud SILVA; ROLIM; MAZOLI, 2016) expõe que a compreensão das Altas Habilidades/Superdotação na década de 1950 estava relacionada com o alto escore do Quociente Intelectual. Esses dados indicam que a avaliação era limitada à aplicação e correção de testes cognitivos, modelo criticado na atualidade. A mensuração era realizada de forma psicométrica, desconsiderando atributos como a criatividade e a motivação. Atualmente, existem diversas escalas validadas pelo Sistema de Avaliação de Testes Psicológicos - SATEPSI. Ao realizar uma busca no sítio, verificou-se que no período dessa pesquisa estão validados e favoráveis catorze instrumentos para a avaliação da inteligência, conforme a tabela 1.

Tabela 1 - Instrumentos para a avaliação da inteligência

INSTRUMENTO
AUTOR (ES)
VALIDADE 
Escala de Inteligência Acácia Aparecida Angeli do Santos; Ana 03/12/2031

Wechsler para crianças Paula Porto Noronha; Fabián Javier Marín

- 4º edição (WISC - IV) Rueda; Fermino Fernades Sisto; Nelimar

Ribeiro de Castro.

Escala de Inteligência Clarissa Marceli Trentin; Denise Balem 18/11/2031

Wechsler abreviada Yates; Vanessa Stumpf Heck.

(WASI)

Escala de Inteligência David Wechsler; Elizabeth do Nascimento

$15 / 10 / 2024$

Wechsler para adultos

(WAIS III)

G-36 Teste não verbal Efraim Rojas Boccalandro;

$27 / 09 / 2023$

de inteligência

G-38 Teste não verbal Efraim Rojas Boccalandro; de inteligência

R-1 Forma B - Teste não Acácia Aparecida Angeli dos Santos; Ana

$01 / 07 / 2025$ verbal de inteligência Paula Porto Noronha; Fermino Fernades Sisto

R-1 Teste não verbal de Iraí Cristina Boccato Alves; Rynaldo de 11/04/2023 inteligência Oliveira

R-2 Teste não verbal de Helena Rinaldi Rosa; Iraí Cristina Boccato 11/04/2023 inteligência para crianças

Teste de Inteligência - TI Fabian Javier Marín Rueda; Nelimar 18/11/2031 Ribeiro de Castro

Teste de inteligência Silésia Maria Veneroso Delphino Tosi;

Geral - Não-verbal (TIG-

NV)

Teste de inteligência Acácia Santos; Ana Paula Noronha; 03/08/2027 não-verbal (TONI-3) Fermino Sisto 


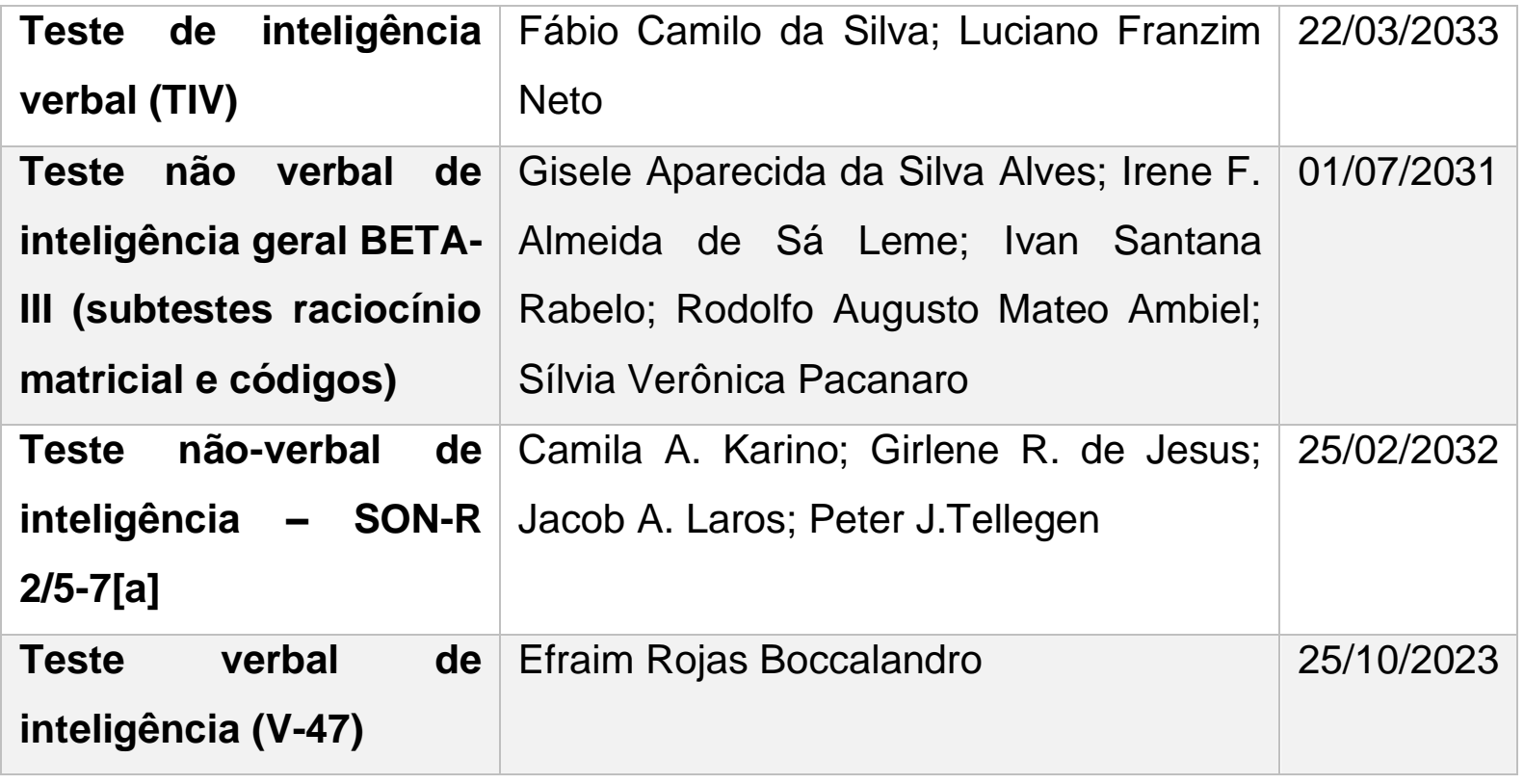

Fonte: Elaborada pela autora (2020)

Hanzin et al (2009) explicam que a comunidade científica faz críticas à construção de instrumentos avaliativos para pessoas com base no Quociente Intelectual - QI, pois não abarcam outras habilidades como a criatividade e as competências artísticas e interpessoais. Por outro lado, existem defesas de que os testes de inteligência podem corroborar na compreensão das funções cognitivas e esclarecer dificuldades escolares e comportamentos sociais. Continuando a análise no sítio do SATEPSI, constatou-se, no período dessa pesquisa, que existem apenas dois instrumentos disponíveis comercialmente para a avaliação da criatividade no Brasil: o Teste de Criatividade Figural e Infantil, dos autores Nakano et al (2015), que consta como aprovado na página na data de 26 de novembro de 2010, com validade até 26 de novembro de 2030, e o Estilos de Pensar e Criar, da autora Solange Muglia Wechsler, aprovado em 01 de dezembro de 2006 e válido até 01 de dezembro de 2026.

Nota-se que embora as habilidades criativas e as competências artísticas sejam campos implementados no que se refere às Altas Habilidades/Superdotação, os instrumentos validados para a mensuração dessas competências no Brasil ainda são escassos. Além do uso de testes psicológicos no processo de avaliação, Almeida e Guenther (2010 apud SILVA; ROLIM; MAZOLI, 2016) propõem o eletroencefalograma 
quantitativo/mapeamento cerebral (EEGQ) como um recurso de confluência entre os testes de inteligência (dados psicométricos), com a finalidade de assegurar uma avaliação criteriosa. A partir dos estudos, constatou-se que os adolescentes com QI alto apresentaram um ritmo predominante de ondas alfas e que os sinais psicofisiológicos emitidos pelo EEGQ permitem relacionar as ondas alfa e o papel do lobo frontal com o $\mathrm{QI}$, o que significa que para identificar pessoas com $\mathrm{AH} / \mathrm{SD}$ é importante a Psicometria com a Neurofisiologia.

Considerando tal contexto, com base nas informações consultadas, constatou-se que existem grandes avanços na área de Neuropsicologia que corroboram para com a compreensão de casos clínicos, e, ainda, para com a realização de planos de tratamento mais adequados para as condições neuropsicológicas do paciente. No entanto, ainda não existe uma classificação precisa nesse campo de estudo para as Altas Habilidades/ Superdotação. Sabe-se, portanto, que a inteligência é um dos fatores para a identificação de um sujeito com AH/SD, mas não há um consenso entre os pesquisadores a respeito do processo de Avaliação. Os dados atuais demonstram avanços na busca de avaliação de outras aptidões: aspectos artísticos, motivacionais e liderança, e, além disso, já existe a associação de resultados dos testes com a neurofisiologia, por meio de exames de neuroimagem.

\subsection{NEUROFISIOLOGIA PARA A COMPREENSÃO DAS ALTAS HABILIDADES/ SUPERDOTAÇÃO}

Considerando os achados históricos, levantou-se dados de que nem sempre o cérebro foi reconhecido como um local importante e relacionado com a mente humana, sendo essa responsável por funções como raciocínio, percepção, capacidade de sentir e tomada de decisões (PAULINO, 2014). Segundo Paulino (2014), as evidências arqueológicas indicam que o homem pré-histórico já suspeitava da ligação entre o cérebro e as funções mentais. Assim, existem evidências históricas de crânios do período neolítico (10.000 a.C.) que possuíam indícios de trepanação, uma técnica cirúrgica que consistia na perfuração do crânio e na retirada de um fragmento. Essa prática era realizada como tratamento para dor de cabeça, epilepsia e traumatismo 
craniano. As pesquisas apontam que o registro mais antigo em referência ao cérebro encontra-se em um papiro egípcio médico divulgado como "Papiro Cirúrgico de Edwin Smith", datado em 1700 a.C., mas que foi relacionado à um período anterior (30002500 a.C.).

A exposição de casos de lesões na cabeça indica que os antigos egípcios também reconheciam que os danos no Sistema Nervoso Central poderiam afetar os comportamentos (FINGER, 1994). Outras significativas contribuições surgiram a partir das pesquisas de Hipócrates (460-377 a.C.) e colaboradores que apontaram o cérebro como a localização da mente. Cerca de dois séculos mais tarde o médico Galeno (130-200 a.C.) também atribuiu funções mentais ao cérebro (PAULINO, 2014). É observável que diversos pesquisadores se preocupavam com o tema e buscavam respostas para o entendimento do cérebro humano. Assim, surgiram diversas teorias e hipóteses, dentre essas a ideia de que o córtex cerebral é composto por áreas de funcionamento distintas. Os dois eventos fundamentais para essa compreensão foram os estudos da frenologia, proposto por Franz Josef Gall (1758-1828) e Joahnnn Spurzheim (1776-1832) e os estudos anátomos clínicos realizados por Paul Broca (1824-1880) (CASTRO; LANDEIRA-FERNANDES, 2012).

Outro destaque nas buscas de compreensão do cérebro e o seu funcionamento ocorreu no ano de 1891, a partir dos trabalhos de Santiago Ramón y Cajal, médico e histologista (1852-1934) que apresentou a unidade básica do cérebro: o neurônio. Desde então, novas informações sobre a sua composição, funcionamento e ação começaram a surgir no campo científico. Cerca de 100 anos após esse marco, na década de 1990, a qual foi denominada como "década do cérebro", foi possível observar pela primeira vez o cérebro humano vivo, consciente e em funcionamento por meio de técnicas de neuroimagem (CASTRO; LANDEIRA-FERNANDES, 2012). Atualmente, conforme descrito por Paulino (2014), uma das grandes investigações dos pesquisadores é a compreensão da ligação entre o cérebro e a inteligência, considerando os indivíduos que possuem capacidades elevadas. 
Em uma busca na base de dados Periódicos CAPES, considerando somente os artigos do século XXI (em qualquer idioma), obteve-se um resultado de 18.472 periódicos, o que demostra grande interesse dos pesquisadores em relação à inteligência. A inteligência é campo de pesquisa de diversos autores, todavia observase definições teóricas distintas. Para Martin (2007 apud VILLAMIZAR; DONOSO, 2013) a palavra inteligência resulta da união logos y nous que significa reunir, juntar, eleger, contar, enumerar, computar, referir, falar; já nous se refere à capacidade de pensar, refletir, perceber e memorizar. Existe ainda a defesa de que a inteligência pode ser classificada em quatro correntes: a Psicometria em duas vertentes: monolíticas e multifatoriais. Na primeira corrente a inteligência é única, inata e mensurável e na segunda há múltiplos fatores que podem ser avaliados com instrumentos de mensuração. Há, ainda, a Desenvolvimentista de Piaget, definida como um processo de adaptação na busca por equilíbrio.

Ele se desenvolve em quatro etapas: hereditariedade, experiência física, transmissão social e a equilibração. Há a Sociocultural proposta por Vigtsky. Diz respeito à formação e desenvolvimento dos processos psíquicos superiores e aos conceitos da zona de desenvolvimento real e proximal. E, por fim, há a Cognitiva, fundamentada por Gardner. É a teoria das múltiplas inteligências (PAULINO, 2014). Conforme Almeida et al (2009), o psicólogo e neurologista Gardner propõe a existência de múltiplas inteligências que se dividem em: musical, linguística, visou-espacial, corporal-cinestésica, lógico-matemática, intrapessoal, interpessoal, naturalística, existencial e espiritual. Para tanto, as pesquisas no campo da neurofisiologia investigam a relação entre a atividade do cérebro e a inteligência de pessoas identificadas com Altas Habilidades/ Superdotação e a inteligência média.

Objetiva-se, com esses estudos, conhecer detalhadamente o funcionamento cerebral e os fatores implícitos à inteligência (PAULINO, 2014). Atualmente, compreende-se que o cérebro é formado por componentes distintos que desempenham diferentes funções. Os módulos corticais responsáveis por essas funções são localizados nos lobos frontais direito e esquerdo. Do ponto de vista da Neuropsicologia, a função executiva abrange os fenômenos de flexibilidade cognitiva e a tomada de decisões 
(MOURÃO JUNIOR; MELO, 2011). O conjunto de informações apresentados nesse capítulo abrange os fatores mais relevantes para a compreensão histórica das AH/SD e a sua correlação com a Neuropsicologia na atualidade. Nessa perspectiva, é possível compreender por que os avanços na temática estão correlacionados com a compreensão do cérebro e as suas respectivas funções.

\section{MECANISMOS NEUROPSICOLÓGICOS DE PESSOAS DIAGNOSTICADAS COM ALTAS HABILIDADES/SUPERDOTAÇÃO}

Esse capítulo abarcará a temática Altas Habilidades/Superdotação considerando a anatomia e biologia do cérebro. Assim, busca-se apresentar dados de pesquisas para a compreensão dos mecanismos neuropsicológicos das pessoas diagnosticadas com AH/SD e os mitos que permeiam a temática. Para Mrazik e Dombrowski (2010 apud BARTOSZECK, 2014), o cérebro humano cresce e se desenvolve desde o período pós-natal até em média os sete anos de idade. Já as ligações sinápticas continuam a se desenvolver além da segunda década. Dessa maneira, o córtex de associação préfrontal direito e inferior que envolve o planejamento antecipatório e a regulação do comportamento emocional evolui até os 20 anos de idade na população avaliada com $\mathrm{AH} / \mathrm{SD}$. Em estudos, verificou-se que o cérebro de meninos e meninas mais inteligentes, submetidos aos testes de avaliação do Quociente Intelectual, desenvolve-se de forma diferente.

Nessa população, foi observado um atraso na maturação e espessura da camada do córtex pré-frontal (função executiva), considerando uma amostra normativa de mais de 300 crianças e adolescentes com idade entre 6 a 19 anos. Esse crescimento mais lento se torna uma vantagem, pois possibilita a formação de conexões sinápticas múltiplas e mais complexas (BLAKEMORE; FRITH apud BARTOSZECK, 2014). Segundo Andrade (2016), o homem nasce com apenas 30\% das suas conexões cerebrais prontas. Essa informação sinaliza que o trabalho de humanização, educação e aprendizagem é o responsável pelas novas ligações sinápticas que serão fundamentais ao desenvolvimento. A pesquisadora esclarece, ainda, sobre a correlação da superdotação com a estimulação após o nascimento. Para tanto, 
explica-se que toda a eficácia de comunicação é estabelecida durante o período prénatal e continua o seu desenvolvimento durante os quatro primeiros anos de idade.

Atualmente, sabe-se que a organização do sistema nervoso (crescimento celular, regulação do tamanho, forma e densidade neural) é influenciada pelos androgénios durante o pré-natal e após o nascimento. Assim, aproximadamente na $8^{\mathrm{a}}$ semana de gestação, os fetos masculinos são expostos à um pico de exposição à testosterona, que, em parte, é responsável pela diferenciação fenotípica dos cérebros feminino/masculino, ou seja, níveis ou sensibilidades aumentadas aos andrógenos no útero poderão acarretar alterações neuro anatômicas (ANDRADE, 2016). Essa teoria defende a existência de uma relação entre a exposição pré-natal de androgênios e superdotação, mas embora seja considerado um modelo lógico e satisfatório, não é aceito por todos os pesquisadores. Pesquisando superdotação, Simonetti (2008) realizou um estudo comparativo dos processos cognitivos a partir de testes psicológicos e indicadores neurofisiológicos. Deu-se como intento nessa pesquisa a investigação das contribuições das ciências neurais na identificação e descrição da superdotação.

Assim, investigou-se por meio da realização de tarefas cognitivas verbais e espaciais, os adolescentes avaliados como superdotados após submissão aos testes de QI. A pesquisadora utilizou como sinal psicofisiológico a atividade cerebral e como técnica o eletroencefalograma quantitativo com mapeamento cerebral. Desse modo, buscouse verificar se a representação neurológica se diferenciava em adolescentes superdotados e não superdotados. Esse estudo contou com a participação de 77 estudantes que frequentam ou frequentaram programas de atendimento para alunos talentosos em Vitória (Espírito Santo, Brasil), com idade entre 11 e 14 anos. Esses alunos foram submetidos a uma avaliação psicométrica - WISC III e considerando os critérios psicológicos foram selecionadas 15 pessoas para 0 exame eletroencefalográfico, dos quais foram divididos em dois grupos: experimental, com QI igual ou superior a 130, e de comparação, com QI acima de 100 e não superior a 120. 
Destaca-se que o registro eletroencefalográfico aconteceu no momento em que os sujeitos realizavam as tarefas cognitivas verbais e espaciais. Os resultados da pesquisa apontaram que no grupo de superdotados foi constante a predominância de alfa, percentil de frequência sempre superior e alta amplitude na realização das tarefas, dado esse que não foi observado no grupo comparativo. A localização das ondas cerebrais se deu de forma predominante nas áreas occipital, pré-frontal e frontal, com dominância do hemisfério esquerdo nos dois grupos. Segundo Simonetti (2008), esses resultados reforçam as hipóteses de que existe uma relação entre o quociente intelectual, a frequência e a amplitude das ondas alfas durante a realização de tarefas e que o EEGQ dos superdotados apontou alto poder alfa, ou seja, menos atividade mental, dado não verificado no grupo de comparação.

Analisando esses achados, questiona-se a respeito dos aspectos neurofisiológicos da superdotação. Ainda de acordo com Simonetti (2018), os estudos e as pesquisas apontam que algumas pessoas são mais propensas ao desenvolvimento da inteligência do que outras, considerando a interação entre a dotação genética e a estimulação ambiental. Dessa forma, pesquisadores levantam a hipótese de que o cérebro dessas pessoas se organiza de forma integrada, flexível e complexa, resultando em funções mais aceleradas e avançadas. Para compreender a presente indagação, faz-se necessário o estudo da anatomia do cérebro e a averiguação de possíveis diferenças entre os sujeitos com altas e médias habilidades. Dentre os esforços para descobrir a correlação das capacidades superiores e a estrutura do cérebro, encontra-se a dissecção (separação em fragmentos) do cérebro do físico Albert Einstein (1879-1955).

As contribuições do cientista auxiliaram na compreensão do espaço e do tempo, das quais pautaram diversos aspectos da física moderna. Segundo a Dra. Silvia Helena Cardoso, da Universidade Estadual de Campinas (2000), em seu artigo "Porque Einstein foi um Gênio?", a autora apresenta contributos da neurofisiologia para essa explicação. A autora faz uma explanação de que o físico morreu em 1955, aos 76 anos de idade, e que o Dr. Thomas Harvey, o patologista que realizou a autópsia, retirou o cérebro de Einstein e doou algumas partes para serem utilizadas em 
pesquisas científicas. A cientista Marian Diamond foi uma das cientistas que recebeu um dos fragmentos do cérebro na década de 80 , e, junto a sua equipe, obteve grandes descobertas. Nessa investigação, contaram o número de neurônios e células gliais no cérebro de Einstein: as áreas nove e trinta e nove do córtex cerebral nos hemisférios direito e esquerdo.

A área nove está localizada no lóbulo frontal (córtex pré-frontal), considerado importante para a elaboração do comportamento, atenção e memória. Já a área trinta e nove está localizada no lóbulo parietal e faz parte do "córtex associativo". Acreditase que essa área seja responsável pela linguagem e outras diversas funções. Os pesquisadores compararam a percentagem de neurônios em relação às células glias com cérebros de outros onze homens que morreram com a idade aproximada de 64 anos. Os elementos encontrados indicaram que Einstein parecia ter uma maior percentagem de células glias. O grupo então concluiu que o maior número de células glias do tipo "oligodendroglia" - células auxiliares que ampliam a velocidade de comunicação neural poderiam ser um indicativo de que os neurônios do cérebro de Einstein apresentavam maior "necessidade metabólica" e, por consequência, usavam mais energia.

Esse é um dado relevante para as habilidades de pensamento demonstradas e para analisar a destreza conceptual. As pesquisas prosseguiram e em junho de 1999 uma equipe do Departamento de Psiquiatria e Neurociências da Faculdade de Ciências da Saúde da McMaster University realizou uma comparação entre o cérebro de Einstein e outros 35 indivíduos, sendo 35 homens e 50 mulheres com inteligência denominada normal. Descobriu-se que o cérebro do físico era cerca de $15 \%$ mais largo na região parietal, em comparação aos demais. Salienta-se que a cognição visuo-espacial, o pensamento matemático e as imagens de movimento são dependentes dessa área. De acordo com os estudiosos, esse elemento pode explicar por que Einstein resolvia problemas científicos com tamanha perspicácia. Além disso, os pesquisadores observaram a ausência de uma fenda na região conhecida como latino de sulcus. 
Assim, especulou-se que essa inexistência pode ter permitido que um número maior de neurônios realizasse conexões e trabalhassem agrupados, possivelmente criando uma extensão grande de córtex integrado dentro de uma rede funcional. Segundo conclusões dessa pesquisa, o que difere umas pessoas de outras na resolução de questões que demandam o uso de funções cognitivas se deve às diferenças estruturais da região do cérebro que intermediam essas funções. Nesse cenário de pesquisas e avanços, diversos estudos neurofisiológicos (EEG) estão surgindo com o objetivo de compreender se existe relação entre a atividade cerebral e a inteligência psicométrica. É importante esclarecer que as ondas cerebrais do EEG mudam de frequência e se baseiam na atividade elétrica dos neurônios e esses se relacionam com as mudanças de estado de concentração para se adaptar a uma tarefa específica (ANTUNES, 2008).

Outro aspecto neurofisiológico importante das Altas Habilidades/Superdotação foi apresentado na pesquisa Alexander, O'boyle e Benbow (1996), sendo esse um estudo eletroencefalográfico (EEG) com adolescentes do sexo masculino e feminino de altas e médias habilidades e contou-se com estudantes universitários de ambos os sexos. A pesquisa tinha como intuito investigar as contribuições relativas dos hemisférios cerebrais direito e esquerdo durante a realização de uma tarefa. Dessa forma, 90 indivíduos tiveram EEG de base registrados em três grupos com números iguais de homens e mulheres, ou seja, 30 adolescentes superdotados, 30 adolescentes com capacidade média e 30 sujeitos em idade universitária. Os resultados demonstram que adolescentes superdotados podem ter um estado de atividade cerebral aprimorado para o desenvolvimento, assemelhando-se ao de adultos em idade universitária.

Outro cientista que merece destaque e considerado como um gênio pela sociedade moderna foi Stephen Hawking, um físico teórico e cosmólogo britânico (1942-2018), que foi portador de uma doença neurodegenerativa: esclerose lateral amiotrófica, da qual o deixou totalmente paralisado, mas, apesar disso, o físico deu seguimento ao desenvolvimento de teorias intelectuais que entraram para a história. Especula-se em pesquisas o interesse dos pesquisadores no estudo do cérebro do físico, porém dados 
mais contundentes à respeito do andamento desses estudos não foram encontrados (OCAMPO, 2018). Atualmente, diversos estudos em neurofisiologia buscam averiguar se existe relação entre a atividade cerebral e a inteligência, dentre esses a utilização de ondas alfas para a compreensão dos aspectos neurofisiológicos da superdotação. Nesse campo, os pesquisadores Gerlic e Jausovec (1999) conduziram uma pesquisa que investigou os processos cognitivos envolvidos na aprendizagem de informações que foram apresentadas em formato multimídia e texto utilizando medidas eletroencefalográficas (EEG).

Participaram 38 alunos, sendo 19 com altas habilidades e 19 com habilidades média. Eles aprenderam com o material que foi apresentado, isto é, na forma de texto, imagem e vídeo, enquanto o seu EEG foi gravado. Nesse estudo, o poder alfa foi analisado e, nos casos de apresentação de texto, as medidas de potência alfa demonstraram maiores amplitudes, o que significa uma menor atividade mental sobre os lobos occipital e temporal e menos poder alfa, ou seja, maior atividade mental sobre os lobos frontais. Os alunos superdotados apresentaram menor atividade mental durante os três formatos de apresentações. Essas diferenças foram principalmente observadas no formato vídeo. Não foram observadas diferenças quantos ao gênero dos participantes nos padrões EEG relacionadas ao formato de apresentação. Outro estudo de grande relevância foi realizado por Jin et al (2007), que teve como principal objetivo a investigação das áreas do cérebro que estão relacionadas a memorização de uma figura complexa.

Assim, considerando o contexto apresentado, é válido destacar que o EEG foi registrado em 18 alunos destros, saudáveis e superdotados antes e depois da memorização da figura. Foram avaliadas as habilidades de memória visou-espacial, planejamento e, também, as funções executivas. Os resultados apontaram que os superdotados obtiveram pontuações altas em comparação com a população média durante a memorização e observou-se, também, a dominância do hemisfério direito nos sujeitos com AH/SD em comparação com a média dos estudantes. Conforme Simoneetti (2000), ainda que os estudos neurofisiológicos da cognição proporcionem 
explicações de alguns fenômenos biopsicológicos como a inteligência e a superdotação, faz-se necessário reconhecer as vantagens e os fatores limitantes.

Para a autora, considerando os resultados apontados nos estudos nos últimos anos, alguns dados neurofisiológicos demonstram a necessidade de pesquisas mais refinadas, como, por exemplo, a arborização dos neurônios corticais, as conexões interneurais e dendríticas, os neurotransmissores, o metabolismo da glicose cerebral e a velocidade de condução nervosa. Os elementos abordados nesse capítulo evidenciaram que o cérebro em sua magnífica anatomia ainda possui muitos campos que demandam pesquisas mais aprofundadas. Considerando os diversos avanços e as pesquisas relacionadas a indivíduos com $\mathrm{AH} / \mathrm{SD}$, observa-se um campo promissor no que se refere ao estudo e a compreensão da biologia do cérebro. O próximo capítulo abarcará a realidade brasileira de crianças e adolescentes com Altas Habilidades/Superdotação na perspectiva escolar, os desafios para os profissionais e os mitos mais comuns.

\section{REALIDADE BRASILEIRA DE CRIANÇAS E ADOLESCENTES COM ALTAS HABILIDADES/SUPERDOTAÇÃO NA PERSPECTIVA ESCOLAR}

Na realidade brasileira existem diversos mitos e compreensões errôneas que resultam na estigmatização das pessoas com AH/SD e reverberam durante a vida desses sujeitos, principalmente em suas trajetórias escolares quando os seus potenciais não são devidamente explorados, gerando insatisfação e evasão da instituição de ensino. Esse panorama também pode ser compreendido na interpretação de Alencar (2007) que afirma:

No Brasil, superdotação ainda é vista como um fenômeno raro e prova disso é o espanto e curiosidade diante de uma criança ou adolescente que tenha sido diagnosticado como superdotado. Observa-se que muitas são as ideias errôneas a seu respeito presentes no pensamento popular (ALENCAR, 2007, p. 15). 
Por consequência dessas crenças, o neuropsicólogo, em sua prática profissional, depara-se com pais e professores apreensivos em relação à identificação e atendimento das pessoas com altas $A H / S D$. Eles se sentem inseguros em indicar características que denotem habilidades acima da média (ARANTES-BRERO, 2018). O desconhecimento dos responsáveis e professores gera medo e o envolvimento deles é primordial, já que os indivíduos com AH/SD necessitam de apoio adequado daqueles que o cercam, em razão de que, em muitas vezes, se sentem desajustados, diferentes e não pertencentes a um grupo. Tanto as famílias como a escola necessitam de esclarecimentos e apoio sobre como lidar com esse sujeito, de modo que o compreendam e o auxiliem no processo de adaptação social, educacional e emocional (ARANTES-BRERO, 2018).

É por essa razão que se faz tão importante a qualificação dos profissionais da educação no processo de identificação dos alunos com AH/SD, de modo a encaminhá-los para que outros profissionais também avaliem o caso, e, de forma multidisciplinar, estabeleçam ou não o diagnóstico de AH/SD. Ressalta-se que profissionais capacitados contribuem com a desmitificação e fornecem melhores subsídios para as dúvidas recorrentes do sujeito e de seus familiares. Conforme Joseph e Renzulli (2018), a sociedade precisa investir em recursos especiais para o desenvolvimento da superdotação, pois a proposta educacional de ensino deve propiciar aos sujeitos o máximo de oportunidades para a autorrealização por meio do desenvolvimento e expressão de um conjunto de áreas de desempenho, de forma que o potencial superior seja explorado.

Assim, ainda segundo os doutrinadores supracitados, será possível aumentar o reservatório de pessoas na sociedade que poderão ajudar a solucionar os problemas da civilização contemporânea, sendo esses os produtores de conhecimento e arte ao invés de meros consumidores de informações preexistentes. Segundo Negrini e Freitas (2008), faz-se importante destacar que a identificação de pessoas com AH/SD não possui o intuito de "rotular" esses indivíduos, formar um grupo de elite, dentre outras colocações que são feitas quanto à essa proposta. O objetivo com a identificação é o fornecimento de atendimentos especializados que contemplem as 
verdadeiras necessidades e interesses desse sujeito para que esse possa ser estimulado e, assim, desenvolver as suas habilidades de maneira satisfatória e com qualidade. A necessidade de maior compreensão quantos aos processos cognitivos de sujeitos com $\mathrm{AH} / \mathrm{SD}$ em situação de desenvolvimento e aprendizagem acadêmica justifica-se conforme os dados encontrados no sítio do Ministério da Educação.

Os estudos internacionais demonstram que o percentual de crianças superdotadas ou com $\mathrm{AH} / \mathrm{SD}$ varia de 10 a $15 \%$. No Brasil, as estatísticas apontam um número menor, devido às dificuldades de identificação que ocorrem nas escolas. Atualmente, ArantesBrero (2018) explica que uma das críticas em relação à escola e ao ensino por essa prestado se deve, principalmente, ao fato de que está assentada predominantemente no pensamento lógico, desencorajando, dessa forma, a divagação, o não saber, livres associações e experiências significativas que levam o aluno a acessar o não familiar por meio do familiar. Em continuidade a temática o próximo sub tópico elenca os principais mitos que dificultam a compreensão e a realização de intervenções mais eficazes que proporcionem o pleno desenvolvimento de pessoas com AH/SD.

\subsection{MITOS}

O artigo Superdotação e seus Mitos, de Antipoff e Campos (2010) apresenta as compreensões equivocadas sobre as Altas Habilidades/Superdotação. Os respectivos temas abordados contribuem para desmistificação, esclarecimento e aprimoramento de programas voltados para os sujeitos com AH/SD e o meio social em que estão inseridos.

1. As pessoas com Altas Habilidades destacam-se em todas as áreas da escola. De acordo com Antipoff e Campos (2010), a superdotação em determinada área, como a matemática, não implica, necessariamente, em uma superdotação em outras áreas, como português e ciências;

2. Todo indivíduo superdotado tem o QI elevado. Conforme as autoras, essa ideia deve ser descartada, pois de acordo com a definição de Winner (1998), existem "indivíduos frequentemente autistas, com Qls na extensão de retardo 
e habilidades excepcionais em domínios específicos". É importante destacar, ainda, que existem crianças superdotadas no campo artístico, mas que não apresentam QI elevado nas demais áreas do conhecimento;

3. A superdotação é inata ou é produto do meio social. O biológico e o cultural influenciam-se mutuamente, não existe um fator mais importante que o outro (HALPERN, 2006 apud ANTIPOFF; CAMPOS, 2010);

4. $O$ indivíduo superdotado também é psicologicamente bem ajustado. $A$ literatura aponta que esses sujeitos podem ser instáveis em razão das tentativas de se igualarem a população média (o que pode ocasionar angústia e perda da identidade). E como pontuado por (NOVAES apud ANTIPOFF; CAMPOS, 2010) outro motivo deve-se a prováveis ridicularizações pelos pares e a falta de maturidade para lidar com as questões que já conseguem compreender racionalmente;

5. As crianças superdotadas se tornam adultos eminentes. Essa é outra ideia equivocada, pois as autoras apontam a citação de Winner (1998) "muitas crianças superdotadas, especialmente os prodígios, malogram, enquanto outras acabam por se dedicar a outras áreas de interesse". Conforme Guenther e Freeman (apud ANTIPOFF; CAMPOS, 2010) a superdotação é algo que o indivíduo trás em potencial desde o nascimento, mas é necessário ser trabalhado esse desenvolvimento, considerando o psicológico e o social;

6. As pessoas com Altas Habilidades provêm de classe econômica elevada. Para Antipoff e Campos (2010) essa é outra crença equivocada de que somente aquelas crianças advindas de famílias de classes mais abastadas terão condições de serem estimuladas e de desenvolverem seus respectivos talentos. As autoras fazem menção ao documento elaborado pelo MEC, Programa de Capacitação de Recursos Humanos do Ensino Fundamental: Superdotação e Talento, (BRASIL, 1999) que aborda o assunto.

7. Não se deve identificar pessoas com Altas Habilidades. É fundamental que os professores saibam como identificar os seus alunos talentosos, de forma que possam encaminhá-los para um atendimento especializado, objetivando $o$ aprimoramento das habilidades, pois é preciso a identificação para que as 
necessidades especiais sejam atendidas (RECH; FREITAS, 2005 apud ANTIPOFF; CAMPOS, 2010).

8. As pessoas com Altas Habilidades não precisam de atendimento educacional especial. Os pesquisadores da área afirmam que é muito importante a identificação desses indivíduos o quanto antes e que um atendimento diferenciado é essencial para que os talentos não sejam desperdiçados e para que haja o fortalecimento do desenvolvimento emocional e psicológico (ANTIPOFF; CAMPOS, 2010).

As questões elencadas por Antipoff e Campos (2010) demonstram a relevância do assunto e o quanto se faz importante a disseminação de estudos e pesquisas cientificas que corroborem para a desmitificação no que se refere às AH/SD.

\subsection{EDUCAÇÃO ESPECIAL - DIREITO DOS ALUNOS COM ALTAS HABILIDADES/ SUPERDOTAÇÃO}

Nesse contexto, faz-se importante compreender a respeito da inclusão para os alunos com AH/SD:

A Política Nacional de Educação Especial na Perspectiva da Educação Inclusiva tem como objetivo assegurar a inclusão escolar de alunos com deficiência, transtornos globais do desenvolvimento e altas habilidades/superdotação, orientando os sistemas de ensino para garantir: acesso ao ensino regular, com participação, aprendizagem e continuidade nos níveis mais elevados do ensino; transversalidade da modalidade de educação especial desde a educação infantil até a educação superior; oferta do atendimento educacional especializado; formação de professores para o atendimento educacional especializado e demais profissionais da educação para a inclusão; participação da família e da comunidade; acessibilidade arquitetônica, nos transportes, nos mobiliários, nas comunicações e informação; e articulação intersetorial na implementação das políticas públicas (BRASIL, 2008). 
O documento explica que durante muito tempo a organização da educação especial, de forma paralela à educação comum, era mais apropriada para a aprendizagem de alunos que apresentavam deficiência, problemas de saúde ou qualquer inadequação à estrutura organizada pelo sistema de ensino. Entretanto, o desenvolvimento de estudos no campo da educação e a defesa dos direitos humanos vêm modificando esses conceitos assim como as legislações e as práticas pedagógicas e de gestão realizaram uma reestruturação do ensino regular e especial (BRASIL, 2008).

Com a Declaração de Salamanca de 1994 fica estabelecido, como princípio, que as escolas de ensino regular devem educar todos os alunos, enfrentando a situação de exclusão das crianças com deficiência e das superdotadas (BRASIL, 2008). Observase que essa proposta de inclusão visa beneficiar todo e qualquer aluno que não se adeque ao sistema regular de ensino, oportunizando alternativas para a sua aprendizagem e consolidação da sua formação. Sendo assim, para a oferta da educação inclusiva aos sujeitos com AH/SD, a Política Nacional de Educação Especial na Perspectiva da Educação Inclusiva define:

Alunos com altas habilidades/superdotação demonstram potencial elevado em qualquer uma das seguintes áreas, isoladas ou combinadas: intelectual, acadêmica, liderança, psicomotricidade e artes. Também apresentam elevada criatividade, grande envolvimento na aprendizagem e realização de tarefas em áreas de seu interesse. Dentre os transtornos funcionais específicos estão: dislexia, disortografia, disgrafia, discalculia, transtorno de atenção e hiperatividade, entre outros (BRASIL, 2008).

Para Matos e Maciel (2016), a definição de alunos com AH/SD fica explícita nesse documento oficial da federação que trata de Educação Especial, e, dessa forma, demonstra que essas pessoas podem manifestar tal condição em várias áreas do conhecimento, em unicidade ou de forma concomitante, o que acarreta no desempenho acima da média quando comparados com outros sujeitos da mesma faixa etária e escolaridade. Por essa razão, denota-se a necessidade de políticas 
públicas que regulamentem um atendimento especializado e direcionado para essa população.

\subsection{RETROSPECTIVA HISTÓRICA DE POLÍTICAS PÚBLICAS BRASILEIRAS}

Realizando uma retrospectiva histórica das políticas públicas no Brasil, Matos e Maciel (2016) apontam que as primeiras prescrições normativas a respeito da formação de professores para atuarem com as necessidades educacionais especiais ocorreram na década de 1960, com a Campanha Nacional de Educação e Reabilitação de Deficientes Mentais (CADAME). Essa campanha corroborou para a aprovação do Decreto ํㅜ 48.961, de 22 de setembro de 1960, cujo documento evidenciava, no Art. 3o, a forma como devia ser desenvolvida a educação, o treinamento e a reabilitação de crianças com necessidades especiais. Entretanto, esse documento não fazia menção à educação especial para AH/SD (MAZZOTA, 2003; JANUZZI, 1992 apud MATOS; MACIEL, 2016). Por conseguinte, aconteceu a primeira menção de Educação para "alunos excepcionais" nas políticas públicas brasileiras, assegurada na Lei de Diretrizes e Bases da Educação Nacional (LDB), aprovada no ano de 1961 (BRASIL, 1961).

Contudo, somente 10 anos depois, em 1971, com a promulgação da Lei 5.692/71 foram incluídas as diretrizes para o ensino de "superdotados" no Art. $9^{\circ}$, o qual afirma que: os superdotados deverão receber tratamento especial, de acordo com as normas fixadas pelos competentes conselhos de Educação (BRASIL, 1971). Posteriormente, no ano de 1973, criou-se o Centro Nacional de Educação Especial (CENESP), vinculado ao MEC, objetivando promover ações educacionais e financiar ações de atendimento para pessoas com necessidades especiais, incluindo as deficiências e as AH/SD (BRASIL, 2008). Assim, a Portaria Ministerial № 550, sobre o CENESP, estabeleceu o seu regimento interno, o qual define, no caput e parágrafo único do Art. $2^{\circ}$, que o CENESP tem por finalidade e planejamento a promoção e o desenvolvimento da Educação Especial no período pré-escolar, nos ensinos de $1^{\circ} \mathrm{e}$ $2^{\circ}$ grau, superior e supletivo para pessoas com deficiência visual, auditiva, mental, 
física, deficiências múltiplas e para os superdotados (MAZZOTTA, 2003 apud MATOS; MACIEL, 2016).

Decorridos 13 anos, ocorreu outro marco importante: o CENESP foi, então, substituído no ano de 1986 pela Secretária de Educação Especial (SESP), responsável pela publicação de manuais para a orientação do ensino de alunos com AH/SD. Alguns anos mais tarde, elaborou-se o Plano Nacional de Educação (Lei Federal no 10.172/01) e as diretrizes Nacionais da Educação Especial na Educação Básica, em setembro de 2001, com a determinação da implantação de atendimentos especializados (MATOS; MACIEL, 2016). Um novo avanço aconteceu com o estudo de Prieto (2004) que realizou um trabalho chamado "Políticas de inclusão escolar no Brasil". Esse estudo retrata as dificuldades de identificação de alunos com AH/SD e a carência de serviços apropriados para esses sujeitos, sendo que, em alguns casos, foi observada a escassez de políticas públicas para esses indivíduos. Conforme descrito por Matos e Maciel (2016), o Fundo Nacional de Desenvolvimento da Educação (FNDE) e as Secretarias de Educação em parceria com a Organização das Nações Unidas para Educação, Ciência e Cultura (UNESCO) instituem os Núcleos de Atividades de Altas Habilidades/Superdotação (NAAH/S).

É interessante destacar, também, considerando o âmbito das políticas públicas, que o NAAH existe desde 2005, com implantação em todos os Estados e no Distrito Federal, e, desse modo, foram formados centros de referência para o atendimento educacional especializado para os alunos com AH/SD. Os núcleos oferecem, também, orientações às famílias e a formação continuada aos professores para atender a esse público (BRASIL, 2008). Esses núcleos representam uma resposta às necessidades sociais e os sujeitos com AH/SD desconsiderados por tantas vezes pelas políticas públicas. Assim sendo, começaram a possuir direitos e serviços adequados que propiciam o pleno desenvolvimento. Após esse levantamento histórico, serão demonstradas as impressões do sistema de ensino e do ambiente escolar por pessoas diagnosticadas com Altas Habilidades/Superdotação. 


\subsection{A VIDA ESCOLAR - RELATOS}

As pesquisadoras Arantes-Brero (2018) apresentam no livro "Altas Habilidades/Superdotação" os processos criativos, afetivos e o desenvolvimento de potenciais em um estudo que mostra as histórias de vida de jovens e adultos diagnosticados com AH/SD. Esses prestaram depoimentos à respeito de como foi a descoberta do diagnóstico, a vida escolar e a relação com o conhecimento, família e meio social. Com ênfase na vida escolar desses sujeitos, apresenta-se três depoimentos dos participantes do estudo[1]: Paulo[2]: "era um local onde havia aulas fáceis e muito tempo livre. Às vezes elas eram monótonas, não por falta de interesse, mas porque eram muito repetitivas".

O entrevistado sempre foi bem tratado pelos professores e reconhece que não era um mau aluno: "Alguns professores, em particular, direcionavam suas perguntas a mim ou a alguns alunos específicos, porque era muito provável de nós sabermos a resposta, transformando a explicação em um diálogo (...). Rafael, por sua vez, aponta que[3]: não gostava da escola e sentia que os seus interesses não eram levados em consideração, "uma cabeça adolescente de esquerda ficava um pouco esquisito num colégio bem careta (...) a partir da 6ำ série, mais ou menos, meus interesses eram outros, não tinha nada a ver com aquela instituição, era uma coisa meio fora do lugar." Em relação às atividades propostas: "eu fazia exatamente o que eles queriam para eles não encherem meu saco e as questões minhas, os meus interesses eu levava à parte, fora do currículo".

Por outro lado, Hollingworth apud Alencar (2002), aponta que alunos excepcionalmente inteligentes (QI igual ou acima de 130), quando possuem a oportunidade de interagir com os seus pares, apresentam mudanças expressivas no comportamento, de modo que o envolvimento e as contribuições nas atividades em grupo se tornam mais significativas. Esse dado pode ser observado na declaração de João[4]: "lembro de várias vezes de gente que me chamava para ir estudar." Nessa época da escola já havia publicado o seu primeiro livro, decorrente de uma atividade proposta pelo professor: "Eu acho que mais isso do que a questão do superdotado 
influi um pouco na minha personalidade, essa coisa de aparecer." Ele era uma celebridade entre os amigos por causa das entrevistas que dava. "eu tava lá dando uma entrevista para a TV e assim que terminou, meus amigos viram, pegaram uns pedaços de papel e queriam que eu autografasse (...) foi bastante divertido".

Considerando esses discursos, é possível compreender como as pessoas com AH/SD entendem o sistema de ensino. Os relatos demonstram que todos possuíam facilidade com as tarefas acadêmicas, fator desencadeante para a desmotivação de alguns deles. Por outro lado, nota-se, em um dos depoimentos, que o acolhimento e o suporte dos colegas de classe contribuíam para um maior engajamento nas atividades. Verifica-se a grande relevância do suporte social, principalmente durante o período acadêmico. O sujeito que obtiver recursos e companheiros capazes de compreendêlo acessará com mais facilidade as suas potencialidades. É por essa razão que se observa a importância das políticas públicas voltadas para esses sujeitos: espaços para a exploração e construção de conhecimentos que sejam significativos para essa população, qualificação de profissionais e orientações para as famílias. Esse capítulo demonstrou significativos avanços nesse campo, todavia, faz-se necessária a ampliação e aprimoramento.

\section{CONSIDERAÇÕES FINAIS}

A reflexão do presente trabalho permite compreender as significativas contribuições e avanços da Neuropsicologia para a compreensão das Altas Habilidades/Superdotação. Considerando o levantamento bibliográfico, constatou-se concordância entre os estudiosos da área que o tema é uma demanda antiga da sociedade, entretanto, os estudos mais refinados são recentes, com limitações e divergências no campo teórico. A investigação dos marcos históricos no capítulo 1 indica que as primeiras abordagens relativas ao tema ocorreram no ano de 1960 e a primeira manifestação do assunto na Política de Educação Brasileira só aconteceu onze anos mais tarde, com a Lei 5.692, de agosto de 1971. Desde então, ocorreram mudanças e reformulações. Além disso, objetivou-se, no primeiro capítulo, apresentar como a Neuropsicologia classifica as Altas Habilidades/ Superdotação. 
Sendo assim, verificou-se que desde os primórdios da área busca-se estudar as habilidades cognitivas, considerando as dificuldades e as habilidades manifestadas cotidianamente. Apesar da preocupação desses estudiosos, foi demonstrado que não existe uma classificação precisa para as AH/SD nesse campo de estudo. Todavia, notou-se que os pesquisadores se preocupam com os processos de classificação da inteligência, e, dentre esses, a avaliação neuropsicológica por meio de testes e instrumentos privativos ao psicólogo. Vale ressaltar que muitos autores defendem que essa avaliação não deve ser limitada à aplicação e correção de testes cognitivos. Nesse capítulo também foi demonstrado que os teóricos apontam a necessidade de compreensão da anatomia e biologia do cérebro nos estudos investigativos da neurofisiologia que visam estabelecer relação entre as atividades cerebrais e a inteligência.

Por conseguinte, abordou-se a respeito dos mecanismos neuropsicológicos de pessoas diagnosticadas com Altas Habilidades/ Superdotação. Os dados apurados apontaram pesquisas que correlacionam às atividades cerebrais com a inteligência $e$ análises quantitativas da atividade cerebral (EEGq). Essas pesquisas demonstraram que os mecanismos neuropsicológicos de pessoas com AH/SD diferem da amostra normativa de outros sujeitos com habilidades médias, considerando a mesma faixa etária e escolaridade. $\mathrm{O}$ que demonstra grandes avanços na área, contudo, ainda existem fatores limitantes que indicam a necessidade de investigação, como a arborização dos neurônios corticais, as conexões interneurais e dendríticas, os neurotransmissores, o metabolismo da glicose cerebral e a velocidade de condução nervosa. O último capítulo desse estudo retratou a realidade brasileira de crianças e adolescentes com Altas Habilidades/Superdotação na perspectiva escolar.

Expõe-se que a falta de conhecimento e compreensões inadequadas ao tema podem resultar na estigmatização dos indivíduos com AH/SD e acarretar danos, principalmente na vida acadêmica. Outro tema de grande relevância explicito nesse capítulo foram os mitos que permeiam os sujeitos com Altas Habilidades/ Superdotação. Dessa forma, apresentou-se uma lista das compreensões errôneas mais comuns no que se refere $\mathrm{AH} / \mathrm{SD}$, de modo que essa corrobore para elucidações 
e esclarecimentos. Dado o exposto, esse estudo demonstrou que ainda existem empecilhos nos processos de reconhecimento dos sujeitos com AH/SD no âmbito escolar, pois faltam profissionais capacitados para a identificação e o devido encaminhamento. Observou-se, ainda, que o diagnóstico deve servir como um aparato para promoção de oportunidades, desenvolvimento e autorrealização.

Considerando esse contexto, fez-se relevante retratar a respeito da educação especial e realizar uma retrospectiva histórica das necessidades dessa população e os reconhecimentos adquiridos em forma de Lei. Nesse levantamento, foi possível constatar que já faz 58 anos desde a primeira menção na Lei de Diretrizes e Bases da Educação - LDB. Paulatinamente, têm-se observado significativos avanços, dentre esses a existência, desde 2005, dos Núcleos de Altas Habilidades/ Superdotação (NAAH/S) em todos os Estados da federação brasileira e no Distrito Federal. Visa-se ofertar atendimento educacional especializado para esses alunos, além de formação continuada para os profissionais e orientações aos familiares. Por fim, o último tópico elencou os depoimentos de pessoas diagnosticadas com $\mathrm{AH} / \mathrm{SD}$ que relataram as suas percepções do sistema de ensino e vivências no ambiente escolar.

Evidenciou-se, a partir dos relatos, que todos tinham muita facilidade com as tarefas escolares e que as atividades propostas não contemplavam as suas verdadeiras necessidades, o que gerava desmotivação. Por outro lado, o suporte social de colegas contribuía significativamente para o engajamento nos estudos. Em análise aos elementos abordados, esse trabalho cumpre com a proposta apresentada nos objetivos específicos, pois por meio dos dados supracitados apresentou-se as contribuições da Neuropsicologia para a identificação e desenvolvimento de pessoas com Altas Habilidades/ Superdotação. Visa-se, portanto, fomentar o interesse de profissionais e estudantes da área e gerar reflexões para novas pesquisas. 


\section{REFERÊNCIAS}

ALENCAR, E. M. L. S. Indivíduos com altas habilidades/superdotação: clarificando conceitos, desfazendo ideias errôneas. A construção de práticas educacionais para alunos com altas habilidades/superdotação, v. 1, p. 16-23, 2007.

\section{ALENCAR, E. M. L. S. O Aluno com Altas Habilidades no Contexto da Educação} Inclusiva. 2002.

Disponível

em:

http://ead.bauru.sp.gov.br/efront/www/content/lessons/32/O\%20ALUNO\%20COM\%2 OALTAS\%20HABILIDADES\%20NO\%20CONTEXTO\%20DA\%20EDUCA\%C3\%87\% C3\%830\%20INCLUSIVA.pdf. Acesso em: 07 mar. 2020.

ALEXANDER, J. E.; O'BOYLE, M. W.; BENBOW, C. P. Developmentally advanced EEG alpha power in gifted male and female adolescents. International Journal of Psychophysiology, v. 23, n. 1-2, p. 25-31, 1996.

ALMEIDA, L. S. et al. Inteligências múltiplas de Gardner: É possível pensar a inteligência sem um factor g? Psychologica, n. 50, p. 41-55, 2009.

ANDRADE, C. D. A. Fundamentos Neurobiológicos da superdotação e Patologia associada Investigação básica. 2016. 50f. Dissertação (Mestrado em Medicina) Faculdade de Medicina da Universidade de Lisboa, Lisboa, 2016.

ANTIPOFF, C. A; CAMPOS, R. H. de. F. Superdotação e seus mitos. Psicologia Escolar e Educacional, v. 14, n. 2, p. 301-309, 2010.

ANTUNES, A. $O$ apoio psico-educativo a alunos com altas habilidades: Um programa de enriquecimento numa escola inclusiva. 2008. 240f. Tese (Doutorado em Psicologia) - Universidade do Minho, 2008.

ARANTES-BRERO D. R. B. Trajetórias de vida de pessoas com altas habilidades ou superdotação. In: VIRGOLIM et al. Altas habilidades/superdotação processos criativos, afetivos e desenvolvimento de potenciais. Curitiba: Juruá, 2018, p. 69-111. 
BARTOSZECK, A. B. Neurociências, altas habilidades e implicações no currículo. Revista Educação Especial, p. 611-626, set. 2014.

BRASIL. Lei no 13.234 de 29 DE dezembro de 2015. Brasília: Presidência da República do Brasil, $2015 . \quad$ Disponível em: http://www.planalto.gov.br/ccivil_03/_ato2015-2018/2015/lei/113234.htm. Acesso em 27 jun. 2018.

BRASIL. Ministério da Educação. Lei no 4.024, de 20 de dezembro de 1961. Lei de diretrizes e bases da educação nacional. Brasília, DF: MEC, 1961. Disponível em: http://www2.camara.leg.br/legin/fed/lei/1960-1969/lei-4024-20-dezembro-1961353722-publicacaooriginal-1-pl.html. Acesso em: 25 fev. 2019.

BRASIL. Ministério da Educação. Lei no 5.692, de 11 de agosto de 1971. Lei de diretrizes e bases para o ensino de 1ำ e 2o graus. Brasília, DF: MEC, 1971. Disponível em: http://www2.camara.leg.br/legin/fed/lei/1970-1979/lei-5692-11-agosto1971-357752-publicacaooriginal-1-pl.html. Acesso em: 25 fev. 2019.

BRASIL. Ministério da Educação. Secretaria de Educação Especial. Política nacional de educação especial na perspectiva da educação inclusiva. Brasília, DF: MEC/SEESP, 2008.

BRASIL. Ministério da Educação. Secretária de Educação Especial. Política Nacional de educação especial na perspectiva da educação inclusiva. Brasília, 2008. Disponível em: http://portal.mec.gov.br/arquivos/pdf/politicaeducespecial.pdf. Acesso em 25. fev. 2019.

CARDOSO, S. H. Por que Einstein foi um gênio? 2000. Disponível em:www.cerebromente.org.br. Acesso em: 16 jan. 2019

CASTRO, F. S.; LANDEIRA-FERNADES, J. Notas históricas acerca do debate mente e cérebro. Com Ciência - SBPC, 2012. Disponível em: 
http://www.nnce.org/Arquivos/Artigos/2012/castro_etal_2012.pdf. Acesso em: 12 fev. 2019.

FERNANDES, M. E. M. C. Anais da 21ª Reunião Anual de Psicologia. Ribeirão Preto, 1991, p 1-20.

FINGER, S. Origins of neuroscience: a history of explorations into brain function. New York: Oxford Press, 1994. Disponível em: https://onlinelibrary.wiley.com/doi/abs/10.1002/ana.410360532. Acesso em: 12 fev. 2019.

GERLIC, I.; JAUSOVEC, N. Multimedia: Differences in cognitiveprocesses observed with EEG. Educ. Technol. Res. Dev., v. 47, n. 3, p. 5-14, 1999.

HAZIN, I. et al. Contribuições do WISC-III para a compreensão do perfil cognitivo de crianças com altas habilidades. Aval. psicol., v. 8, n. 2, p. 255-265, ago. 2009.

JIN, S. H. et al. Differences in EEG between gifted and average students: Neural complexity and functional cluster analysis. The International Journal of Neuroscience, v. 117, 1167-1184, 2007.

JOSEPH, S.; RENZULLI. Reexaminando o papel da educação para superdotados e o desenvolvimento de talentos para o Século XXI: uma abordagem teórica em quatro partes. In: VIRGOLIM. et al. Altas habilidades/superdotação processos criativos, afetivos e desenvolvimento de potenciais. Curitiba: Juruá, 2018, p. 19-42.

LÜDKE, M; ANDRÉ, M. E. D. A. Pesquisa em educação: abordagens qualitativas. São Paulo: EPU, 1986.

MATOS, B. C.; MACIEL, C. E. Políticas Educacionais Brasil e Estados Unidos para o Atendimento de Alunos com Altas Habilidades/ Superdotação (AH/SD). Rev. Bras. Ed. Esp., v. 22, n. 2, p. 175-188, abr./jun. 2016. 
MERLO, S. O aluno com altas habilidades superdotação e sua inclusão na escola. 2008. 25f. Artigo monográfico - Universidade Federal de Santa Maria, Rio Grande do Sul, 2008.

MIOTTO, E. C; LÚCIA, M. C. de.; SCAFF, M. Neuropsicologia clínica. Rio de Janeiro: Roca, 2018.

MOURÃO JUNIOR, C. A; MELO, L. B. R. Integração de três conceitos: função executiva, memória de trabalho e aprendizado. Psic.: Teor. e Pesq., v. 27, n. 3, p. 309-314, set. 2011.

NAKANO, T. de. C. et al. Bateria para avaliação das altas habilidades/superdotação: análise dos itens via Teoria de Resposta ao Item. Estud. psicol., v. 32, n. 4, p. 72974, dez. 2015.

NEGRINI, T.; FREITAS, S. N. A identificação e a inclusão de alunos com características de altas habilidades/superdotação: discussões pertinentes. Revista "Educação Especial", n. 32, p. 273-284, 2008.

PAULINO, C. E. O cérebro e suas possíveis relações com altas habilidades. UNESP, [2014?]. Disponível em: http://atividadeparaeducacaoespecial.com/wpcontent/uploads/2014/07/O-CEREBRO-E-SUAS-REL\%C3\%87\%C3\%95ES-COMAS-ALTAS-HABILIDADES.pdf. Acesso em: 12 fev. 2019.

PRIETO, R. G. Políticas de inclusão escolar no Brasil: descrição e análise de sua implementação em municípios das diferentes regiões. In: REUNIÃO DA ASSOCIAÇÃO NACIONAL DE PÓSGRADUAÇÃO E PESQUISA EM EDUCAÇÃO (Anped), 27., Caxambu, 2004. Anais... Caxambu: Anped.

PRIMI, R. et al. Competências e habilidades cognitivas: diferentes definições dos mesmos construtos. Psic.: Teor. e Pesq., v. 17, n. 2, p. 151-159, ago. 2001.

SEVERINO, A. J. Metodologia do trabalho científico. 23a․ ed. São Paulo: Cortez, 2007. 
SILVA, W. G. da.; ROLIM, R. G. B; MAZOLI, W. de. H. Reflexões sobre o processo neuropsicológico de pessoas com altas habilidades/superdotação. Gerais, Rev. Interinst. Psicol., v. 9, n. 2, p. 195-210, dez. 2016.

SIMONETTI, D. C. Superdotação: Estudo comparativo da avaliação dos processos cognitivos através de testes psicológicos e indicadores neurofisiológicos. 2008. $196 f$. Tese (doutorado em educação) - Universidade do Minho, Braga, 2008.

VILLAMIZAR, G; DONOSO, R. Definiciones y teorías sobre inteligencia. Revisión histórica. Psicogente, v. 16, n. 30, p. 407-423, 2013.

\section{APÊNDICE - REFERÊNCIAS DE NOTA DE RODAPÉ}

2. Arantes, D. R. B. Uma Investigação Sobre Pessoas Com Altas Habilidades/Superdotação: dialogando com Marion Milner. 2011. 107 f. Dissertação (Mestrado em Psicologia Clínica) - Pontifícia Universidade Católica, São Paulo, 2011.

3. *Nome fictício.

4. *Nome fictício.

5. *Nome fictício.

Enviado: Agosto, 2019.

Aprovado: Março, 2020. 